\title{
Novelty versus retrieval cue value of visual contextual stimuli in pigeons
}

\author{
DAVID R. THOMAS and SPENCER K. MORRISON \\ University of Colorado, Boulder, Colorado
}

\begin{abstract}
Thomas and Empedocles (1992) proposed that in a retention test, the relative enhancement of responding when the context that had accompanied training is again present might reflect suppression of responding by the alternative test context rather than memory retrieval due to the training context. In Experiment 1, pigeons trained to keypeck in the presence of a (red or blue) colored houselight later responded substantially more in testing in the presence of the training houselight color rather than the alternative color. In Experiment 2, exposure to the (red or blue) houselight color preceded keypeck training under a white houselight condition for one group; for a second group, it followed it. Neither group showed a significant "preference" for the familiar houselight color during testing, whereas a control group, trained as in Experiment 1, did. Thus a contextual stimulus present during reinforced training can help to retrieve the memory of that training experience, as demonstrated by testing strategy which controls for a novelty effect of the nontraining context condition.
\end{abstract}

It is common practice to define a retrieval cue as a feature of the (internal or external) environment that is present during acquisition of a target memory but incidental to the definition of the target task (see Spear, 1978). If the subject notices that feature during acquisition, performance on a retention test should be facilitated to the extent that the feature is also present (and noticed) at the time of testing.

Investigations of the role of the environmental context as a retrieval cue often use a procedure that Balsam (1985) has called the context change method. Subjects are trained in a particular context and are later tested for retention of the target response in that context and/or in a distinctively different one. The typical finding of less responding in the different context may reflect retrieval cue value of the training context, but it may also reflect interfering behaviors induced by the novelty of the nontraining context (see Bindra, 1959). Spear (1978) acknowledged this problem and warned that a disruption in performance in a changed context could only be attributed to the absence of retrieval cues if the disruptive effect of novelty could be ruled out. Unfortunately, he gave no instructions for how this should be accomplished. In a recent paper, Thomas and Empedocles (1992) have suggested a way.

Suppose that one can demonstrate that subjects perform a target response better in the presence of a familiar than [in that of] a novel environment when neither could serve as a retrieval cue because neither was present during ac-

\footnotetext{
We wish to thank Michelle Smith for assistance in the collection of data and Eric Wiertelak for performing a pilot study that preceded the present work. Requests for reprints should be addressed to D. R. Thomas, Department of Psychology, Campus Box 345, University of Colorado, Boulder, CO 80309-0345.
}

quisition. This would provide a baseline level of preference for the familiar environment. If the level of preference is reliably greater when the familiarity was gained during acquisition of the target behavior, that difference (between preference levels) would demonstrate a retrieval cue effect independent of familiarity. (p. 23)

Thomas and Empedocles (1992) used the proposed strategy to determine whether the odor present during reinforced keypeck responding in pigeons would serve as a retrieval cue in a subsequent test. In Experiments 1 and 3 of their paper, they showed that pigeons pecked substantially more (in extinction) in the presence of an odor that had been present when keypecking was not possible (because the key was covered) than in the presence of a novel odor. The experiments differed in whether the odor exposure took place prior or subsequent to keypeck training in an odor-free environment, and the order of these experiences was irrelevant. Both experiments demonstrated a strong familiarity (novelty) effect. In Experiments 2 and 4, pigeons were exposed to an odor during reinforced keypeck responding, thereby giving the odor the potential to be associated with that response and thus to serve as a retrieval cue. These subjects also "preferred" the familiar odor, but no more so than did the subjects for which the odor was merely familiar (i.e., those in Experiments 1 and 3). Thus it was concluded that the odor present during training had not acquired the function of a retrieval cue.

The study by Thomas and Empedocles (1992) illustrated the error that could result when researchers accept evidence of retrieval cue value on the basis of the context change method without independent evidence that the effect cannot be attributed to novelty alone. The authors did not claim that no contextual cue could pass this rigorous test, only that odors did not. It is possible, for instance, 
that visual contextual cues might succeed where odor cues have failed. Pigeons are highly visual organisms that discriminate grain from nonfood items (such as pebbles) on the basis of their visual characteristics. There is no evidence to suggest that olfaction plays any role in pigeons' feeding behavior; thus, the birds may be contra-prepared to associate odors with food-reinforced behavior (see Seligman, 1970). Furthermore, the size of the novelty effect may be greater in the case of odors than in the case of other contextual stimuli. Thomas and Empedocles (1992) observed that, when first placed in a novel odor environment, birds engaged in "exploratory" behaviors, such as stretching of the neck, sidewise movements of the head, and so forth, which could conflict with the target response of keypecking. Responses to novel contextual cues of another sort-visual ones, for example-might not affect the target behavior to the same extent.

The present study was designed to apply the test used by Thomas and Empedocles (1992) to a visual contextual stimulus, the color of the houselight that was continuously present in the operant chambers. Experiment 1 was performed to determine whether more responding would occur during an extinction test in the presence of a houselight color that had been present during reinforced keypecking than during an extinction test in the presence of a novel houselight color. Once this was established, Experiment 2 was performed to determine whether this difference could be attributed to a retrieval cue effect or could be explained entirely on the basis of novelty.

\section{EXPERIMENT 1}

In Experiment 1, pigeons received keypeck training in the presence of either a blue or a red houselight. They were later tested, in extinction, for response strength in the presence of each of these two houselight colors. It was predicted that the subjects would respond more in the presence of the houselight color that had accompanied training than in the alternative houselight color. Pilot research had suggested that the acquisition of control over keypecking by the houselight color would take considerably longer than is the case with key color or line angle discriminative cues. This was taken into account in the design of the present experiments.

\section{Method}

Subjects. The subjects were 7 common pigeons obtained from a local supplier and maintained at $80 \%$ of their normal body weight. The birds were housed individually in a colony room with a 12:12-h light:dark cycle. Light onset was at 6:00 a.m., and sessions were conducted 7 days a week.

Apparatus. Two sound-attenuating ice chests with interior dimensions of $36 \times 35 \times 31 \mathrm{~cm}$ served as the experimental chambers. Each had a wire-mesh floor. One wall, constructed of aluminum, served as the intelligence panel. A 1.9-cm diameter translucent plastic response key centered $19 \mathrm{~cm}$ above the floor. A $4 \times 6 \mathrm{~cm}$ aperture, $13 \mathrm{~cm}$ directly below the key, allowed the pigeons access to mixed grain from a solenoid-operated hopper.
Key stimuli were produced by IEE projectors (Series 0010) with No. 1864 lamps operated at $24 \mathrm{~V}$. The projectors allowed the presentation of a $0.2-\mathrm{cm}$-wide white vertical or horizontal line on a dark background. Chamber illumination was provided by one red and one blue Christmas tree lamp mounted behind a $3 \times 31 \mathrm{~cm}$ light-diffusing Plexiglas panel that extended across the chamber above the intelligence panel. The brightness of the two houselights was controlled by a Variable Autotransformer (Staco Energy Products, Type 2 pf 1010) and was set at levels judged by several human observers to be comparable for the two colors. The red and blue houselight conditions provided the two contexts used in the examination of the effect of visual context on responding. The only other source of light in the chamber was an ESB 24-V lamp mounted behind the intelligence panel, which illuminated the food hopper during food presentation.

An exhaust fan provided masking noise. Reinforcement consisted of a 3-sec access to the food hopper, which was filled with mixed grain. All recording and control was accomplished with a Commodore 128 computer in an adjoining room.

Procedure. In this experiment, as well as in Experiment 2, the houselight conditions were counterbalanced, with approximately half the subjects exposed to red and half exposed to blue. Of the 7 subjects in Experiment 1, Birds 17, 18, 19, and 20 were trained to peck a vertical white line on an otherwise dark key in a blue houselight condition, whereas Birds 25, 27, and 28 were trained to peck a horizontal line in the presence of a red houselight. The different line angles were used for convenience; the computer program was set up this way for another experiment. The line angle used with a given subject should have been irrelevant, since the same line angle was used for training and testing. All subjects initially received extensive hopper training and keypeck training with a gradually lengthening interreinforcement interval. This phase of training lasted 13 days. The birds were then exposed to eleven 30min sessions of training on a VI 30-sec reinforcement schedule during which the keylight was on for 55 -sec periods separated by 5 sec periods when the keylight was off and food was unavailable. The houselight was on when the subjects were placed in the chambers, and remained on throughout each session until the subjects were removed.

The subjects were tested in extinction on the 25 th day. The key stimulus present was the one with which each subject had been trained. The two houselight colors were randomly alternated during 55-sec stimulus-on periods. During the 5-sec stimulus-off periods, both the houselight and the keylight were turned off. The test session lasted $30 \mathrm{~min}$.

\section{Results and Discussion}

The number of responses that each subject emitted in each houselight condition is shown in Figure 1. All subjects responded substantially more in the familiar (training) houselight color condition than in the novel color condition. For purposes of statistical analysis, the number of responses given to each test stimulus by each subject was entered into a houselight color (red vs. blue) $\times$ test context (trained vs. novel color) analysis of variance (ANOVA). There was no main effect of houselight color $(F<1)$ but the difference between responses in the trained and novel colors was highly significant $[F(1,5)=$ $31.60, p<.01]$.

It is clear from the results of Experiment 1 that the houselight color that had accompanied reinforced training controlled the target behavior. It remained to be de- 


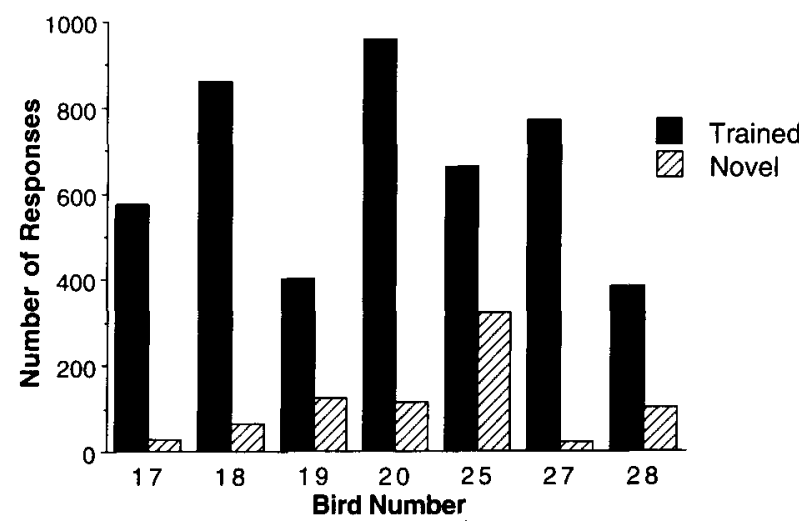

Figure 1. Responses of individual subjects under trained and nontrained (novel) houselight conditions. For Birds 17, 18, 19, and 20 , the color of the houselight during training was blue; for Birds 25, 27 , and 28 , it was red.

termined whether this control could be explained on the basis of familiarity alone.

\section{EXPERIMENT 2}

Experiment 2 was modeled after Experiments 1 and 3 in the Thomas and Empedocles (1992) paper. In this experiment, exposure to a houselight color was separated from the acquisition and performance of the keypeck response; in one group, it preceded keypeck training, whereas in another group, it followed it. For a third (control) group, exposure accompanied reinforced training as in Experiment 1, but testing was delayed.

\section{Method}

Subjects. Twenty-seven experimentally naive pigeons obtained locally were maintained at $80 \%$ of their normal body weights. They were housed in individual cages in a colony room with a $12: 12-\mathrm{h}$ light:dark cycle. Light onset was at 6:00 a.m., and the birds were run daily.

Apparatus. The apparatus was the same as that used in Experiment 1 , with the addition of a white houselight, produced by a No. 1820 bulb operated at $24 \mathrm{~V}$.

Procedure. Three groups of subjects were selected from a total of 27 birds. Group Before had 8 birds: Birds 76, 77, 78, and 79 were exposed to a blue houselight for 24 days and then trained to peck a vertical line on a key in the white houselight for 28 days; Birds $80,81,82$, and 83 were exposed to a red houselight for 24 days and then trained to peck a horizontal line on a key in the white houselight for 28 days. Group After had 8 birds: Birds 64, 65, 66, and 67 were trained to peck at a vertical line on a key in a white houselight for 28 days and then exposed to a blue houselight for 24 days; Birds 68, 69, 70, and 71 were trained to peck a horizontal line on a key in a white houselight for 28 days and then exposed to a red houselight for 24 days. These first two groups were counterbalanced to control for possible forgetting of either the houselight color (Group Before) or the on-key stimulus at which keypecking was directed (Group After). During the sessions of houselight exposure for Groups Before and After, no reinforcement was available and the key was covered. Group During had 11 birds: Birds 90-94 were trained to peck a vertical line on a key in a blue house- light; Birds 95-100 were trained to peck a horizontal line on a key in a red houselight. Group During subjects were magazine and keypeck trained for 24 days, so that their exposure to the colored houselight would be equal to the exposure of Groups Before and After. These subjects were then placed in the chamber illuminated with the white houselight for $\mathbf{2 8}$ days to equate for the amount of time they were exposed to the chamber overall. No food was available during these placement sessions, and the key was covered. All training and placement sessions lasted $30 \mathrm{~min}$.

All groups were tested in extinction on the 53rd day. The pigeons were presented the appropriate vertical- or horizontal-line stimulus on all trials. The red and blue houselight colors were randomly alternated on a trial-by-trial basis. As in Experiment 1, the randomization of houselight colors was arranged by computer, so the starting colors and the entire sequences were different for different subjects. The test session was $30 \mathrm{~min}$ long with each trial lasting $55 \mathrm{sec}$, separated by 5 -sec blackouts during which both the houselight and the key light were turned off.

\section{Results and Discussion}

The test results of the subjects in Group After (keypeck training preceded placement) are not presented here. Only 2 of the 8 subjects in this group responded substantially during testing. One of these "preferred" the placed (familiar) color but the other "preferred" the novel one. Most subjects did not respond at all during testing. It is unlikely that the pigeons would have forgotten the keypeck response during the 24 days of houselight exposure; Skinner (1950) showed retention of the keypeck response over a period of 4 years! A more plausible interpretation is that the experimental chamber with the colored houselight present came to signal the unavailability of food; that is, it became a Pavlovian conditioned inhibitor. This inhibition then generalized to the alternative color.

The test results of the subjects in Group Before (houselight color placement followed keypeck training) are presented in the top panel of Figure 2. One subject, Bird 82, responded so little during testing ( 12 total pecks) that its data were omitted from statistical analysis and the figure. Of the other 7 birds, 3 responded substantially more in the presence of the placed (and thus familiar) houselight color, whereas 2 others actually "preferred" the novel color. A houselight color (red vs. blue houselight placement) $\times$ test context (placed vs. novel) two-way ANOVA was performed on the number of responses. The main effect of houselight color and the interaction between houselight color and test context were not significant $(F<1)$. However, there was a marginally significant difference between the number of responses emitted in the placed and novel contexts $[F(1,5)=4.42, p=.09]$. These results suggest that there may be a novelty-familiarity effect, but its magnitude is substantially less than that among the subjects that were trained in Experiment 1.

The results of Group Before suggest that familiarity with a houselight color cannot account for the overwhelming "preference" for that color shown in Experiment 1. However, it may be that the subjects forgot the houselight color, since 28 days of training intervened between houselight color placement and testing. To evaluate this possibility, Group During was tested 28 days after their train- 

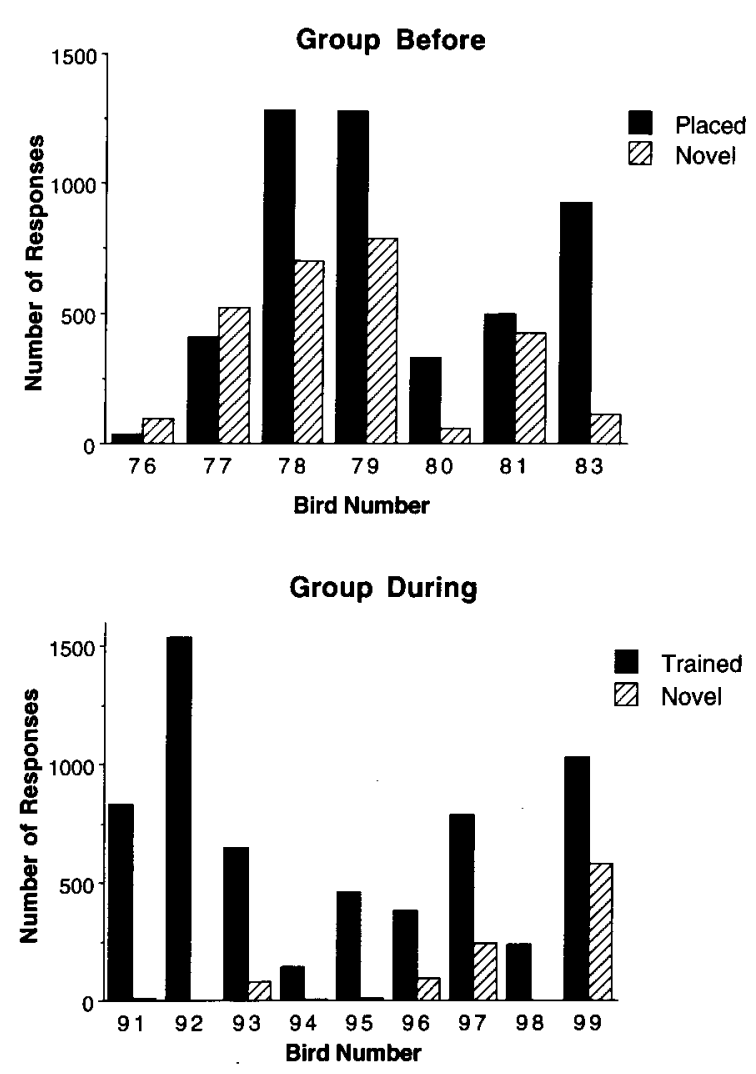

Figure 2. Top: Responses of individual subjects under familiar (placed) and novel colored houselight test conditions. For Birds 76, 77, 78, and 79, the placed houselight color was blue; for Birds 80, 81, 82, and 83, it was red. Bottom: Responses of individual subjects under trained and nontrained (novel) houselight conditions when tested after a 24-day delay. For Birds $91,92,93$, and 94, the color of the houselight during training was blue; for Birds 95, 96, 97, 98, and 99 , it was red.

ing in the houselight color. This group was run after Group Before and Group After, and it was larger than the others in anticipation of the possibility that some subjects might fail to respond during testing.

The results of Group During are presented in the lower panel of Figure 2. Two of the 11 subjects (Birds 90 and 100) failed to respond during testing; their data are not included in the figure or in subsequent analyses. For all the other 9 birds, however, responding was substantially greater in the presence of the houselight color that had been present during training. Indeed, several birds did not respond at all in the novel houselight color condition. A houselight color (red vs. blue) $\times$ test context (trained vs. novel) two-way ANOVA was run on the number of responses emitted in extinction. The preference for the trained context was highly reliable $[F(1,7)=17.94, p<$ $.01]$, while the main effect of houselight color and the interaction between houselight color and test context were not significant $(F<1)$. The fact that strong control was demonstrated by the trained houselight color after a de- lay of 28 days suggests that the minimal level of control by the placement color in Group Before was not simply due to the forgetting of that color during the delay interval.

The difference between whether placement in the context occurs with training or separate from training is evident. Group Before shows little or no control of the placed context over responding, whereas both the immediately tested group (of Experiment 1) and Group During (of Experiment 2) show strong control of the trained context over responding. To evaluate the difference statistically, an analysis compared the percentage of responses to the placed (or trained) context in Group Before and Group During. The percentage of responses given to the training stimulus during a generalization test has become a common measure of stimulus control. It has the advantage of allowing high- and low-responding subjects to contribute equally to the group average performance, and it eliminates a major source of variance in operant situations (i.e., that of large individual differences in response rate). Group During was chosen for the comparison because its experience was most like that of Group Before. (The results would have been the same had the group from Experiment 1 been used instead.) A two-way (houselight color: red vs. blue $\times$ experience: placed vs. trained) ANOVA was used to make the comparison. There was a main effect of experience $[F(1,12)=13.13, p<.01]$ and the houselight color by experience interaction was significant $[F(1,12)=7.64, p<.05]$. A closer look at the interaction revealed that the red subgroups did not differ significantly on the basis of whether they were placed or trained in the red environment $[t(6)=.55, p=.60]$. The percentages of responses given to the red context were 76.03 under the placement condition and 82.40 under the training condition. On the other hand, the blue subgroups yielded a higher percentage of test responses in the trained context than in the placed context $[t(6)=5.12, p<.01]$. The percentages of responses given to the blue stimulus were 49.23 under the placement condition and $\mathbf{9 6 . 5 0}$ under the training condition. This analysis points out that the demonstration of a retrieval cue versus a novelty effect depended on whether the red or blue houselight was present during placement or training.

\section{GENERAL DISCUSSION}

The size of the novelty effect shown by Thomas and Empedocles (1992) was so large that it might have been difficult to show a retrieval cue effect in addition to that novelty effect. This was not the case in the experiments reported here. Despite 24 sessions of exposure to a colored houselight in Experiment 2, the extent of "preference" for the familiar color in Group Before was only of borderline significance. We do not wish to argue that there is no novelty effect with houselight color contextual stimuli. For 4 of the subjects, the "preference" for the familiar color was substantial, whereas the birds "preferring" the novel color did so less strongly and tended to make fewer responses during testing. It seems likely that 
with a larger group of subjects, the group average "preference" for the familiar houselight color would achieve statistical significance. This is almost certainly the case for subjects placed in the red houselight condition. What is required to demonstrate a retrieval cue effect is greater "preference" for the familiar houselight color when that familiarity has been achieved in the context of reinforced training. In the present study, in which a substantial novelty effect was absent, a retrieval cue effect could be and was revealed. It may turn out that the failure to find evidence for a retrieval cue effect with odors was the exception, rather than the rule, probably because of the combination of a ceiling effect and the difficulty birds may have in associating odor with food-reinforced behavior.

The present study indicates that a visual contextual cue, houselight color, can pass the test that Thomas and Empedocles (1992) suggested was necessary for demonstrating that a contextual cue, by virtue of mere presence during reinforced training, can acquire the capacity to retrieve the memory of that training. This finding is of considerable theoretical significance. Most studies of memory retrieval performed with animal subjects circumvent the problem of distinguishing a novelty effect from a retrieval cue effect by explicitly training subjects to make different responses in different contexts. However, demonstrating that contextual stimuli can be made to control behavior is insufficient support for the claim that they normally do so. If explicit discrimination training were necessary to establish contextual stimuli as effective retrieval cues, this would seriously undermine McGeoch's (1932) proposal that a change in contextual cues accounts for much of normal forgetting. The results of the present study are thus consistent with McGeoch's premise.

When visual contextual stimuli are shown to exert control over behavior directed toward on-key visual stimuli, the possibility needs to be addressed that the control is indirect; that is, that it occurs because of changes in the appearance of the on-key stimuli. This interpretation does not seem reasonable in the present case. Because the houselight was mounted behind and at the top of the intelligence panel and the key was recessed slightly into the panel, no light from the Christmas tree bulb shined directly on the key. In addition, no tint of the houselight color on the key was apparent to human observers.

A more direct test is provided by an unpublished experiment performed in our laboratory in which pigeons were trained on the daily reversal of a conditional discrimination: on some days, the houselight was blue and the birds were reinforced for pecking vertical and not horizontal; on alternate days, the houselight was red and the opposite contingency was in effect. When the birds had mastered this conditional discrimination, they were shifted to a task that was the same, except that we substituted red and blue key colors for the red and blue houselight colors. There was little evidence of positive transfer; the birds did not acquire the new conditional discrimination any faster because of their previous experience with the old one. This finding supports the supposition that in the present experiments the control exerted by the houselight colors is direct and not mediated via changes in the appearance of the key stimuli.

An important yet unexpected finding in these experiments was that the particular houselight color used in training or in placement had a substantial effect on the results. Thus, subjects trained to keypeck in the presence of the blue houselight seemed to show stronger "preference" for their training color than did those trained to respond in the presence of the red houselight. On the other hand, subjects placed (not trained) in the red houselight seemed to show a stronger "preference" for their placement color than did those placed in the blue houselight. Both of these effects fell short of conventional statistical significance, but their combination had a major impact. If only the red houselight had been used in placement and training in this study, we would not have been successful in demonstrating a retrieval cue effect. Strong evidence for that effect comes from the fact that subjects showed no "preference"' for the blue houselight unless they were trained to keypeck in its presence.

We have recently observed a similar discrepancy in the effectiveness of red and blue houselights as conditional cues indicating which of two line angles to peck at. In an experiment carried out by Morrison, Lusby, and Thomas (1993, Experiment 1), a single reversal procedure was used, such that the birds first learned to peck vertical and not horizontal in the presence of one of the two houselight colors and later learned to do the opposite under the alternative color. Line angle generalization testing was then carried out in extinction, with the houselight colors alternating in blocks of test trials. In the subgroup for which the red houselight accompanied Phase 1, strong evidence for conditional control was obtained, with the gradients tending to show maximal responding to the line angle appropriate to the houselight color present at the time. On the other hand, when the blue houselight accompanied Phase 1, the strong tendency was for subjects to show recency - that is, to "prefer" horizontal regardless of which houselight color was present at the time. Like the present study, the work of Morrison et al. emphasizes the need for the counterbalancing of conditions in the study of behavioral control by contextual stimuli.

Because the blue houselight was always paired with the vertical line in the present experiments and the horizontal line was always paired with the red, the possibility must be considered that it is not the blue houselight that is a better retrieval cue but rather the vertical line. This interpretation is inconsistent with the finding by Morrison et al. that when the red houselight had accompanied Phase 1 and the blue houselight had accompanied Phase 2, the horizontal line exerted as much control during generalization testing when the red houselight was present as the vertical line did when the blue houselight was 
present. Furthermore, in an earlier single-reversal study performed by Thomas, McKelvie, and Mah (1985), in which the white houselight was either on or off in the two training phases, the line angle generalization gradients showed equally strong control by horizontal and vertical discriminative cues. In each case, the gradient peaked sharply at the line angle that had been reinforced under that houselight context condition. Thus, it seems clear that the anomalous results produced by red and blue houselight contextual stimuli in the present experiment cannot be attributed to differences in the effectiveness of horizontal versus vertical line angle cues. At present, we have no explanation for why blue and red houselight contextual cues produce the results that they do.

In conclusion, on the basis of the results of the present study, we may safely conclude that a visual contextual cue, present at the time of reinforced learning, can help pigeon subjects retrieve the memory of the training experience if that cue is also present during the retention test. The strategy used in this study can separate the possible effect of novelty or familiarity from that of a true retrieval process. We recommend that it be generally adopted for that purpose in future research on memory retrieval using the context change method.

\section{REFERENCES}

Balsam, P. D. (1985). The functions of context in learning and performance. In P. D. Balsam \& A. Tomie (Eds.), Context and learning (pp. 1-21). Hillsdale, NJ: Erlbaum.

BINDRA, D. (1959). Stimulus change, reactions to novelty, and response decrement. Psychological Review, 66, 96-103.

McGeoch, J. A. (1932). Forgetting and the law of disuse. Psychological Review, 39, 352-370.

Morrison, S. K., Lusby, E. K., \& Thomas, D. R. (1994). An analysis of conditional control in pigeons: Further comparison of simultaneous and serial presentation. Manuscript submitted for publication.

Seligman, M. E. P. (1970). On the generality of the laws of learning. Psychological Review, 77, 406-418.

SkinNer, B. F. (1950). Are theories of learning necessary? Psychological Review, 57, 193-216.

SPEAR, N. E. (1978). The processing of memories: Forgetting and retention. Hillsdale, NJ: Erlbaum.

Thomas, D. R., \& Empedocles, S. (1992). Novelty vs. retrieval cue value in the study of long-term memory in pigeons. Journal of Experimental Psychology: Animal Behavior Processes, 18, 22-33.

Thomas, D. R., McKelvie, A. R., \& MAH, W. L. (1985). Context as a conditional cue in operant discrimination reversal learning. Journal of Experimental Psychology: Animal Behavior Processes, 11, 317-330.

(Manuscript received March 24, 1993; revision accepted for publication June 18, 1993.) 